\title{
Protective antigen domain 4 of Bacillus anthracis as a candidate for use as vaccine for anthrax
}

\author{
Dorota Żakowska ${ }^{1, C-D, F \oplus}$, Grzegorz Graniak ${ }^{1, E \oplus}$, Paweł Rutyna $^{1, C \oplus}$, Katarzyna Naylor ${ }^{2, D} \oplus$, \\ Patrycja Głowacka ${ }^{1, A \oplus}$, Marcin Niemcewicz ${ }^{1, E \oplus}$ \\ 1 Biological Threats Identification and Countermeasure Center of the General Karol Kaczkowski Military Institute of \\ Hygiene and Epidemiology, Puławy, Poland \\ 2 Department of Didactics and Medical Simulation, Medical University, Lublin, Poland \\ A - Research concept and design, B - Collection and/or assembly of data, C - Data analysis and interpretation, \\ $D$ - Writing the article, $E$ - Critical revision of the article, $F$ - Final approval of article
}

\begin{abstract}
Żakowska D, Graniak G, Rutyna P, Naylor K, Głowacka P, Niemcewicz M. Protective antigen domain 4 of Bacillus anthracis as a candidate for use as vaccine for anthrax. Ann Agric Environ Med. 2019; 26(3): 392-395. doi: 10.26444/aaem/99669

\section{Abstract}

Existing research for using the protective antigen (PA) of Bacillus anthracis as a vaccine component shows that protection against anthrax may be obtained using fragments of this protein. The aim of the research is to check whether the selected protein fragment of the protective antigen (domain 4) encoded by an appropriate nucleotide sequence of gene pag of $B$. anthracis, was expressed in the bacterial system of $E$. coli. In order to examine the selected sequence of the pag gene, a PCR reaction and a highly effective TOPO cloning strategy were used, followed by purification of the recombinant proteins and their detection by a western-blot method. In the planning of the PA4 antigen expression a higher level of effectiveness in production of small protein - domain 4 - was anticipated. As a result, the 139 amino acids protein fragment of $B$. anthracis PA (domain 4) was isolated. The research may have found the basis for in vivo research aimed at finding potential anthrax vaccine components.
\end{abstract}

\section{Key words}

Bacillus anthracis, cloning pag gene, domain 4, protective antigen, protein, recombinant, vaccine

\section{INTRODUCTION}

Anthrax is a contagious, highly dangerous and acute zoonotic disease caused by Gram-positive Bacillus anthracis. Pathogenicity of $B$. anthracis depends on the presence of two plasmids in the genome - pXO1 and pXO2. Genes pagA, lef and cya located on pXO1 (approx. size $182 \mathrm{~kb}$ ) are responsible for coding protein subunits of anthrax toxin (protective antigen - PA, lethal factor - LF and edema factor - EF), whereas cap gene on pXO2 (around $95 \mathrm{~kb}$ ) codes the poly- $\gamma$ d-glutamic acid capsule $[1,2,3]$.

PA protein, known also as PA 83, consists of 735 amino acids and its molecular weight is $82.684 \mathrm{kDa}$. The gene pagA, coding PA protein, contains an open reading frame (ORF) consisting of $2319 \mathrm{bp}$, where 2205 determine the sequence of 735 PA protein amino acids [4].

The three-part structure of the PA83 protein consists of 4 domains, structurally independent and joined together to form a higher complexity structure [5].

Domain 4 of the PA protein binds with the receptor ATR (anthrax toxin receptor) on the cell surface. Next, PA is proteolytically activated by the cell's furin protease. In the heptamer, the PA63 monomers form a ring, where the domains 1 and 2 are positioned inside, and 3 and 4 are located on the outside of the heptamer (PA63) ${ }_{7}[6]$.

Address for correspondence: Dorota Żakowska Biological Threats Identification and Countermeasure Center of the General Karol Kaczkowski Military Institute of Hygiene and Epidemiology, Puławy, Poland, Lubelska 2 St., 24-100 Puławy, Poland e-mail: dzakowska@wihe.pulawy.pl

Received: 18.07.2018; accepted: 09.11.2018; first published: 05.12.2018
Recent findings indicate that the mentioned medicaments may be less effective in the case of antibiotic-resistant strains of $B$. anthracis. Consequently, a potent vaccine for anthrax has become a pressing target worldwide - an alternative to antibiotic treatment in a form of pre- and post-exposure prevention. An immune reaction is a complex process where, apart from antibodies, cell mediated immune response plays a part. Detectable in blood and countable PA antibodies do not fully indicate the immunity level of an organism, although their presence is necessary to protect the organism from infection $[7,8]$.

However, the vaccines produced in UK and USA require repeated applications with less than desirable outcomes. The British vaccine AVP (anthrax vaccine precipitated) is administered 4 times in 3 doses every 3 weeks and the 4 th dose after 6 months. The booster dose is given every 12 months. On the other hand, there is the American AVA (anthrax vaccine adsorbed) registered in 1970 in the the USA, at Michigan Biologic Products Institute, Lansing. Since 2002, the vaccine has been sold under the name Biothrax. It is administered 6 times in 3 doses every 2 weeks, then 3 additional doses after 6,12 and 18 months plus, yearly boosters $[9,10]$

Nowadays, vaccines containing PA are criticized due to the inability to standardize the preparation (different consignments of the vaccine may have different content); the necessity of repeated administration and booster doses; frequent side-effects, short-lasting immunity, and lack of immunity to some strains of $B$. anthracis [11].

As a result of these concerns, investigations have been undertaken in an effort to produce and test the immunological 
effectiveness of the recombined PA protein (rPA). The protein, obtained with modern technology, may easily be purified, concentrated and used for the purposes of prophylaxis.

\section{MATERIALS AND METHOD}

The vaccine strain of $B$. anthracis $34 F 2$ Sterne from the collection of BTICC (Biological Threat Identification and Countermeasure Centre) MIHE in Pulawy, Poland, was used in the research. DNA isolation was performed using a Genomic Mini kit (A\&A Biotechnology) according to the manufacture's recommendations. In amplification, DNA isolated from the Bacillus anthracis 34F2 Sterne strain was used as template DNA.

In PCR reactions, appropriate primers were used, flanking the region of domain 4 of PA B. anthracis $34 \mathrm{~F} 2$. The primers (synthesized by Genomed JSC, Poland) for the pagA region (GenBank No.AF268967, http://www.ncbi. nlm.nih.gov/entrez) studied contained CACC sequences d4F: CACCGTTGGGGCGGATGAG $(10 \mu \mathrm{M})$ and d4R: TCTCCTTGTATTTCTTACAAAAAGAGT $(10 \mu \mathrm{M})$ were used in amplification (475 bp fragment) of an appropriate thermal profile with other reagents: Taq $(5 \mathrm{U} / \mu \mathrm{l})$ DNA polymerase, polymerase buffer (10 x buffer Taq), 2 mM DTP, 25 $\mathrm{mM} \mathrm{MgCl}_{2}$ (Fermentas, Lithuania) and isolated matrix DNA. The PCR program was as follows: an initial denaturation of $95^{\circ} \mathrm{C}$ for 3 minutes, 30 rounds of $30 \mathrm{~s}$ denaturation at $95^{\circ} \mathrm{C}$, $30 \mathrm{~s}$ annealing at $53^{\circ} \mathrm{C}$, and 2 minutes of extension at $72^{\circ} \mathrm{C}$, followed by 10 minutes of final extension at $72^{\circ} \mathrm{C}$.

The products of amplification were separated in $1 \%$ agarose gel. The blunt-end amplified fragment was ligated into expression vector pET 100/D-TOPO (Invitrogen, USA) and fused in-frame with $6 \mathrm{xHis}$ tag. Constructed plasmid was propagated in E. coli using One Shot TOP 10 (Invitrogen, USA) and incubated at $37^{\circ} \mathrm{C}$ on LB agar plates containing ampicillin $(100 \mu \mathrm{g} / \mathrm{ml})$. Selected transformant (by collecting 5 chosen colonies from the selective plate), were transferred to the liquid growing medium (LB medium) containing ampicillin $(100 \mu \mathrm{g} / \mathrm{ml})$ and incubated overnight at $37^{\circ} \mathrm{C}$ with shaking. After incubation, the genetic materials was isolated using a Plasmid Miniprep Plus kit (A\&A Biotechnology, Poland). The received recombined plasmids were subjected to sequence analysis in DNA Sequencing Lab of Genomed JSC (The DNA sequences presented as chromatograms were compared with the sequence of pagA Bacillus anthracis str. A2012 plasmid pXO1 NCBI No. AF268967). As a efficiency control the pUC19 plasmid was used, with the same reaction conditions.

For protein expression, the second transformation was performed. In the first step, the $10 \mathrm{ng}$ of purified plasmid DNA, from the first transformation, was used to transform E. coli Star BL21 (DE3) (Invitrogen, USA). The transformed cells were grown in LB medium containing $100 \mu \mathrm{g} / \mathrm{ml}$ ampicillin at $37^{\circ} \mathrm{C}$ until the optical density at $600 \mathrm{~nm}$ was 0.5-0.8. After that, the production of PAD4 was induced by incubating with $1 \mathrm{mM}$ IPTG for 1-4 hrs. For checking the intensity of induction after each $1 \mathrm{~h}$ incubation, the $500 \mu \mathrm{l}$ was sampled. The cells were lysed under native conditions using lysis buffer containing $50 \mathrm{mM} \mathrm{NaH}_{2} \mathrm{PO}_{4}, 300 \mathrm{mM}$ $\mathrm{NaCl}, 10 \mathrm{mM}$ imidazole, prepared according to the Ni-NTA Spin kit procedure (Qiagen, Germany). Cell pellets, before purification under native conditions, were frozen for at least 30 minutes at $-20^{\circ} \mathrm{C}$ and resuspended in lysis buffer and an addition of lysozyme $(1 \mathrm{mg} / \mathrm{ml})$ and benzonase nuclease ( $3 \mathrm{U} / \mathrm{ml}$ culture volume).

The intracellularly bacterial protein produced in induction was purified in the process of affinity chromatography using Ni-NTA Spin Kit (Qiagen, Germany), and recombined proteins purification kit 6xHis-tagged. The proteins purified in native conditions were separated on polyacrylamide gel SDS-PAGE. Over-expressed proteins were detected by Western-blotting method (Biorad System, USA) on nitrocellulose membrane (N8267, Sigma-Aldrich) using the TBS buffer with $0.05 \%$ Tween 20 . Immunodetection of the recombinant PAD4 was performed using His HRP Conjugate Kit (1:2,000, Qiagen). Following transfer, the membrane was blocked with 5\% dry milk in TBST buffer and developed with DAB (3,3'-diaminobenzidine tetrahydrochloride) substrate (Roche, Germany) which facilitated a colour reaction.

\section{RESULTS AND DISCUSSION}

The research was undertaken to obtain a recombinant protein (domain 4) of the PA (139 amino acids) and to demonstrate its expression. For this purpose, primers were designed based on the DNA sequence encoding 4 domain of the antigen $\mathrm{PA}$, using the CACC sequence for the forwarder. It was necessary in cloning into a linearized pET-TOPO vector allowing for direct cloning without enzyme digestion. A 475 base pair structure gene for PA was PCR amplified (Fig. 1) and successful inserted into the plasmid pET 100/D-TOPO. Due to the fact that unforeseeable difficulties may occur (e.g. purified protein or its fragment may show no expression, form inclusion bodies, turn out to be difficult to purify or show no required activity) during designing the expression construct, the research used the vector pET 100/D-TOPO. The TOPO (TA cloning vector) study was used in the study by Krishnancgettiar et al. (2003) [12]. In order to obtain the $16,347 \mathrm{kDa}$ domain of protein PA-D4, they omitted enzyme digestion by virtue of this vector and used competent cells of E. coli BL21 (DE3) pLysS.

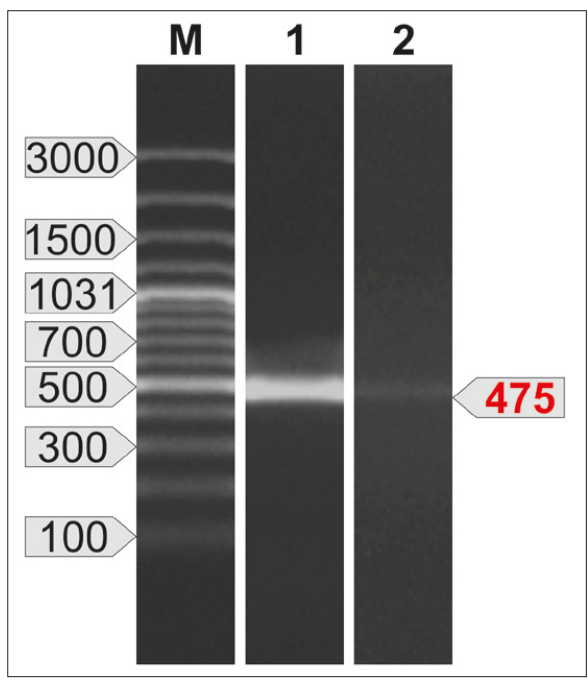

Figure 1. $P C R$ amplification of $p a g$ gene. The $P C R$ product was electrophoresed on $1 \%$ agarose gel and visualized under violet lamp. M - 100 bp DNA ladder, Lane 1 - PCR product of PAD4 (475 bp), Lane 2 - purification PCR product of PAD4 (475 bp) 
The over-produced E. coli bacteria can be accumulated in the cytoplasm, periplasma or secreted outside the cell. The prevalent problem in locating recombinant proteins in the cytoplasm of bacterial cells is the formation of inclusion bodies. However, even if inclusion bodies are formed, a portion of the protein usually remains soluble [12]. Willhitea and Blanke (1998) proved this in their work when they obtained soluble, recombined PA protein in E. coli using a weaker concentration of IPTG $(0.1 \mathrm{mM}$ IPTG) and lowered the induction temperature $\left(16^{\circ} \mathrm{C}\right)$. Using singlestage purification, they obtained an homogenous PA which was stable, could be recovered from $E$. coli lysates, and there was no evidence of proteolytic degradation [13]. Producing recombined proteins is often the only or the cheapest method of obtaining homogenous protein allowing the study of its structure and function $[10,14]$. Suryanarayan and et al. obtained biologically active recombinant PA using pET32c vector. The expression construct PA-pET32c in E. coli DE3$p L y s S$ host resulted in maximum production of recombinant PA in soluble form $(15 \mathrm{mg} / \mathrm{ml})$. The study highlights the expression of soluble recombinant PA in larger quantity using simpler E. coli production platform [10].

Research performed Pavan and et al. using Gateway pENTR/D-TOPO technology for cloning pagA gene and transformed into competent E. coli One Shot TOP10, Expression plasmids pEXP17-pagA were generated by sitespecific recombination using LR clonase II, between the pENTR/D-TOPO-pagA plasmid previously obtained and the destination vector pDEST17 using the E. coli Expression System kit from Gateway Technology, with transformation of competent E. coli One Shot TOP10. The expression plasmids were used to transform competent E. coli BL21Star (DE3)pLys One Shot to obtain expression clones verified by sequencing. The high expression of PA obtained by Pavan and et al. combined with the low background and the enrichment of PA in the lysis step, facilitated PA purification using only washes, without the need for chromatographic purification steps [15].

The results obtained in the present work show that after transforming the resulting construct into a competent $E$. coli cell, bacterial cultures were conducted to overexpress the PA protein encoding gene under induction. As a result of induction, the bacterial cells produced domain $4(\sim 16 \mathrm{kDa})$, which was subsequently purified by under native conditions and separated on SDS-PAGE polyacrylamide gel (Fig. 2). Already after elution of the lysates (lysates 5, 6) visible bands of $\sim 16 \mathrm{kDa}$ were observed. After II elution (lysates 7, 8), strands of $\sim 16 \mathrm{kDa}$ had a slightly weaker intensity. As a result of the protein transfer to the nitrocellulose membrane, it was confirmed that the resulting protein was domain 4 of PA 16 kDa fragment (Fig. 3).

The lysates purified under native conditions on the Ni-NTA field for domain 4 obtained in the tests revealed $16 \mathrm{kDa}(475$ bp) eluates in the western blot. Test conditions were selected (linear vector, E. coli expressing cells, $1 \mathrm{mM} \mathrm{IPTG,} 37^{\circ} \mathrm{C}$ ) to achieve the intended goal as quickly as possible, and by the use of tools facilitating the work and eliminating the possibility of error.

The research of Rezaee et al. supplied valuable information on obtaining the PA protein and particularly its domain 4 after they cloned and expressed domain 4 sequences of the PA protein (PAD4) in E. coli. The research used the vector $\mathrm{pET}$ $28 \mathrm{a}+$ and expression cells E. coli BL21(DE3)PlysS. Following the purification of PAD4 protein by affinity chromatography

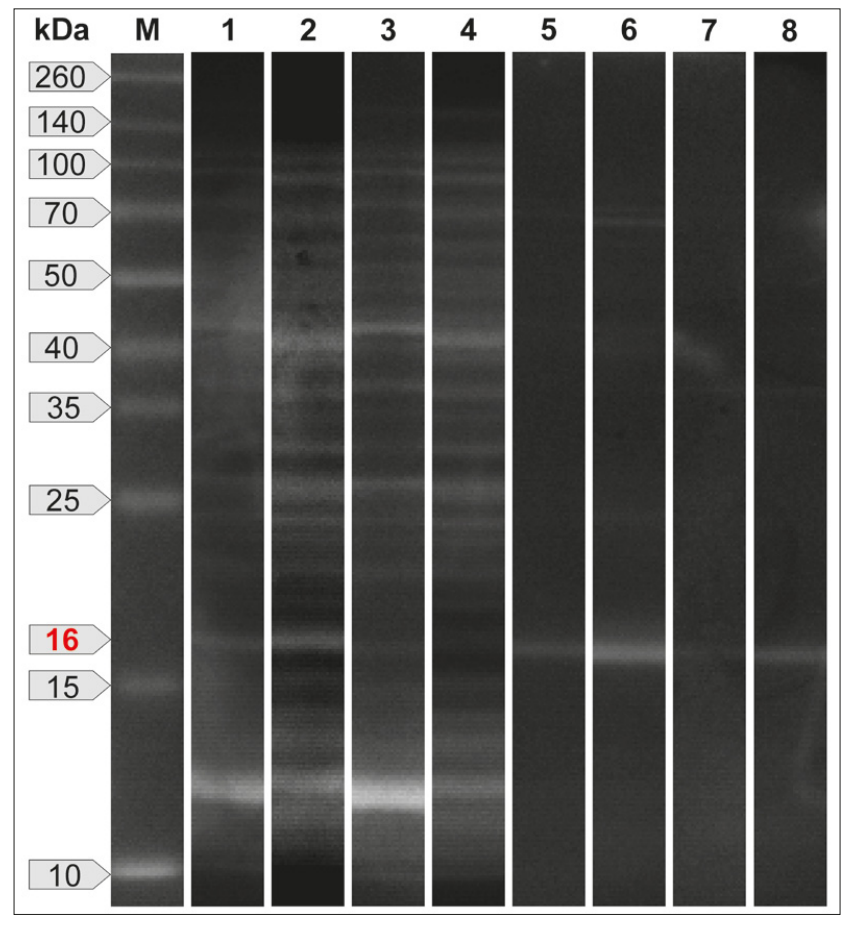

Figure 2. SDS-PAGE electrophoresis of unpurified and purified recombinant protein PAD4 by Ni +-NTA chromatography. $\mathrm{M}$ - protein molecular weight marker Spectra Multicolor Broad Range Protein Ladder (\#26634), Fermentas, Lanes 1, 2, 3,4 - unpurified protein from soluble fractions, Lanes 5, 6- purified protein from soluble fractions (cell lysates after the I elution), Lanes 7, 8 - purified protein from soluble fractions (cell lysates after the II elution)

using the matrix Ni+-NTA and western-blot analysis, they showed the presence of a $28 \mathrm{kDA}$ protein $(600 \mathrm{bp})$ [16].

The purified protein administered to mice presented immunogenic properties through polyclonal antibodies

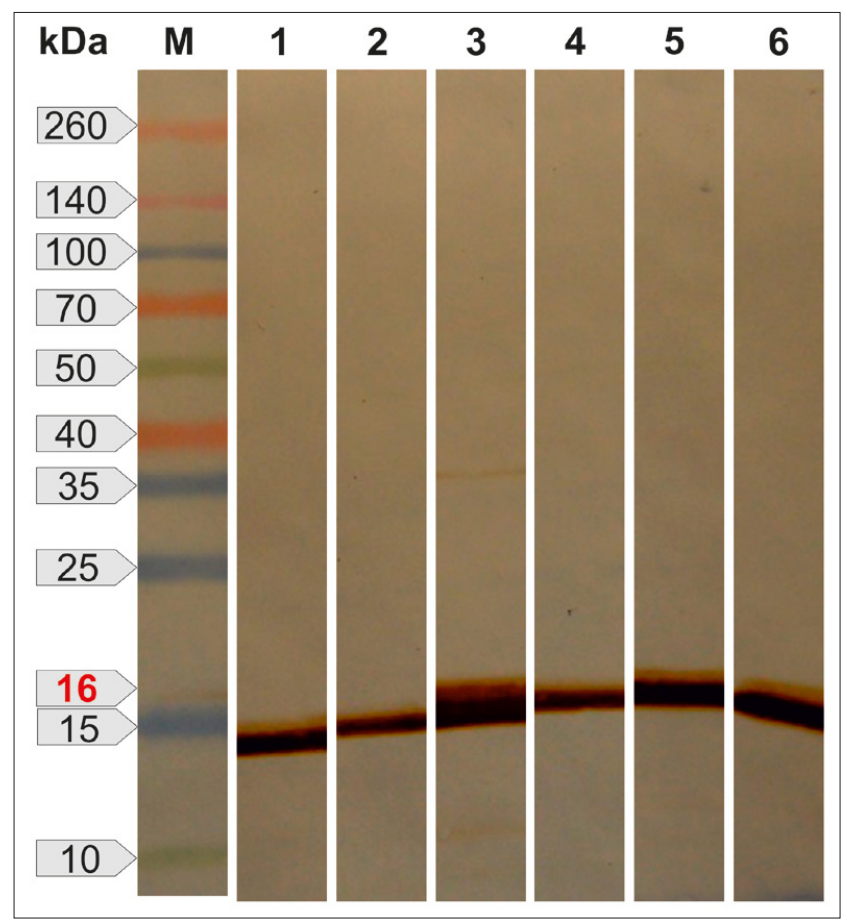

Figure 3. Western blotting of purified recombinant protein PAD4. Lane $\mathrm{M}$ - protein marker Spectra multicolor broad range protein Ladder (\#26634), Fermentas, Lane 1 - $30 \mathrm{ml}$ lysate after Il elution, Lane $2-5 \mathrm{ml}$ lysate after Il elution, Lane $3-30 \mathrm{ml}$ lysate after l elution), Lane $4-5 \mathrm{ml}$ lysate after I elution, Lanes 5, 6 - purified recombinant protein PAD4 $(\sim 16 \mathrm{kDa})$ after 3 and $4 \mathrm{~h}$ respectively induction 
production. This indicated the possibility of using PAD4 as the main ingredient of an anthrax vaccine [16].

Research into the immunogenicity of various domains of PA antigen, including its domain 4, was carried out by Varshney and Goel [3] who cloned and expressed PA domains. Purified recombinant proteins were used to immunize mice that exhibited high antibody titers. The highest immunological response was observed after immunization with the 3 and 4 PAD3-4 domains. The PAD3-4 protein of the PA protein showed a larger immunity response than the PAD1-2, PAD23 and PAD1 domains [3].

Neutralizing antibodies to Bacillus anthracis protective antigen mediate protection against anthrax. To explore the relationship between PA structure and antigenicity, Abboud and Casadevall produced $E$. coli strains expressing domain 4 and evaluated the immunogenicities and protective efficacies of the protein fractions in four mouse strains $\mathrm{A} / \mathrm{J}, \mathrm{BALB} / \mathrm{c}$, C57BL/6 and Swees Webster.

Immunization with protein containing domain 4 was significantly less effective in eliciting high-titer or neutralizing antibody responses. The inability of the domain 4 recombinant protein to elicit neutralizing antibody responses is in contrast to the observation that many neutralizing MAbs bind to this domain. Identified epitope in the region of aa $678-697$ domain 4 . This peptide segment includes residues in and near a solvent-exposed loop of domain 4 (aa 679 to 693) that play critical role in receptor binding and that are recognized by several neutralizing MAbs to PA. [17]

In concordance with current vaccinology goals, producing a recombinant vaccine is a chance to accomplish the aim of safe and effective anthrax vaccine. Such a vaccine would fulfill the modern safety criteria as it contains one or more highly immunogenic components of the pathogen which cannot trigger the disease process particular to the living pathogen, even an attenuated one, and which may be included in recombined vaccines.

A particular interest of scientists is directed towards production of a new generation of recombined vaccines containing on immunogenic causing a high antibody response PA domain 4, a component of anthrax toxin.

\section{REFERENCES}

1. Brossier F, Mock M. Toxins of Bacillus anthracis. Toxicon. 2001; 39(11): 1747-1755.

2. Gierczyński R. Diagnostics and molecular epidemiology of Bacillus anthracis. Post Mikrob. 2010; 49(3): 165-172 (in Polish).

3. Varshney A, Goel AK. Development of recombinant domains of protective antigen of Bacillus anthracis and evaluation of their immune response in mouse model for use as vaccine candidates for anthrax. J Bioterror Biodef. 2016; 7: 147, doi: 10.4172/2157-2526.1000147

4. Welkos SL, Lowe JR, Eden-McCutchan F, Vodkin M, Leppla SH, Schmidt JJ. Sequence and analysis of the DNA encoding protective antigen of Bacillus anthracis. Gene. 1988; 69(2): 287-300.

5. Flik-Smith HC, Walker NJ, Gibson P, Bullifent H, Hayward S, Miller J, et al. A recombinant carboxy-terminal domain of the protective antigen of Bacillus anthracis protects mice against anthrax infection. Infect Immun. 2002; 70(3): 1653-1656.

6. Petosa C, Collier RJ, Klimpel KR, Leppla SH, Liddington RC. Crystal structure of the anthrax toxin protective antigen. Nature. 1997; 385(6619): 833-838.

7. Ivins BE, Welkos SL. Recent advances in the development of an improved, human anthrax vaccine. Eur J Epidemiol. 1988; 4(1): 12-19.

8. Turnbull PC. Anthrax vaccines: past, present and future. Vaccine. 1991; 9(8): 533-539.

9. Chomiczewski K. Vaccines against anthrax. Wakcynologia, BielskoBiała a-Medica Press; 2005; 394-397 (in Polish).

10. Suryanarayana N, Vanlalhmuaka, Mankere B, Verma M, Thavachelvam $\mathrm{K}$, Tuteja U. Soluble expression and characterization of biologically active Bacillus anthracis protective antigen in Escherichia coli. Mol Biol International. 2016; 2016: 1-11, http://dx.doi.org/10.1155/2016/4732791.

11. Żakowska D, Kocik J, Bartoszcze M. Selected research problems of anthrax vaccine development. Prz Epidemiol. 2009; 63(4): 505-512 (in Polish).

12. Krishnanchettiar S, Sen J, Caffrey M. Expression and purification of the Bacillus anthracis protective antigen domain 4. Protein Expr Purif. 2003; 27(2): 325-330.

13. Willhite DC, Blanke SR. Soluble expression and one-step purification of recombinant Bacillus anthracis protective antigen. Prot Pept Let. 1998; 5(5): 273-278.

14. Nuc P, Nuc K. Recombinant protein production in Escherichia coli. Post Bioch. 2006; 52(4): 448-456 (in Polish).

15. Pavan ME, Pavan EE, Cairo FM, Pettinari MJ. Expression and refolding of the protective antigen of Bacillus anthracis: A model for highthroughput screening of antigenic recombinant protein refolding. Rev Argent Microbiol. 2016; 48(1): 5-14.

16. Rezaee M, Honari H, Kooshk MRA. Cloning, expression and purification of binding domains of lethal factor and protective antigen of Bacillus anthracis in Escherichia coli and evaluation of their related murine antibody. Mol Biol Rep. 2014; 41(4): 2445-2452.

17. Abboud N, Casadevall A. Immunogenicity of Bacillus anthracis protective antigen domains and efficacy of elicited antibody responses depend on host genetic background. Clin and Vaccine Immunol 2008, 15(7) 1115-1123. 